\title{
If You Give a Bird a Binary
}

\author{
Mary Kelly
}

Mary Kelly graduated in 1981 with a certificate in early childhood education from Camosun College, Victoria, British Columbia. After many satisfying years working in a variety of childcare settings, Mary returned to Camosun College in the fall of 2008 to obtain a diploma with an infant/toddler specialization in the early learning and care program. After graduating in 2009, Mary was fortunate to join University of Victoria Child Care Services, where she loves working in one of their toddler programs. Email: monkelly@shaw.ca

For the past two years a group of early childhood educators who work for the University of Victoria Child Care Services have voluntarily participated in a course facilitated by two pedagogistas. Each month one or two articles are put forward for reading. Course participants then meet to share their thoughts, struggles, and learning from the readings. As one of the participants, I do my best to read and, more importantly, try to understand and make meaning of the articles. I find it necessary to read the articles multiple times because the academic language used is not part of my everyday early childhood educator vocabulary! It was after I read and reread an article titled "Challenging Anthropocentric Analysis of Visual Data: A Relational Materialist Methodological Approach to Educational Research" by Karin Hultman and Hillevi Lenz Taguchi that I was inspired to write the following poem.

If you give a bird a binary

She'll ask you for two nests.

Once you've found the right materials

She'll decide what suits them best.

It depends on definitions

Knowledge, theories, and beliefs.

Two eggs would be most common,

Most suited, cause less grief.

But what if epistemology

Is foremost on your mind?

A belief lends one suggestion,

Your truths another kind.

To justify one's decision

Puts to question one's beliefs.

Are eggs the chosen objects?

No questions, just relief.

You know that birds lay eggs-

It's infallible, needs no proof.

It's simple, easy, obvious-

Unless you seek more truths.

Could the nests hold brand new knowledge?

Inviting questions from a few:

What phenomenon is occurring

When you question what to do? 